\title{
Formula of Thermogradient Effect
}

\author{
Zviad Kovziridze \\ Georgian Technical University, Institute of Bionanoceramics and Nanocomposites Technology, Tbilisi, Georgia \\ Email: kowsiri@gtu.ge
}

How to cite this paper: Kovziridze, $\mathrm{Z}$. (2018) Formula of Thermogradient Effect. Journal of Electronics Cooling and Thermal Control, 8, 49-54.

https://doi.org/10.4236/jectc.2018.84004

Received: November 5, 2018

Accepted: December 25, 2018

Published: December 28, 2018

Copyright $\odot 2018$ by author and Scientific Research Publishing Inc. This work is licensed under the Creative Commons Attribution International License (CC BY 4.0).

http://creativecommons.org/licenses/by/4.0/

\begin{abstract}
Goal: Formulation of empiric formula, which establishes relations between major matrix parameters of ceramic materials and composites and the coefficient of resistance to material thermogradient. Method: Harcpurt's method of cooling of water in boiling regime till disappearance of water. Results: It is proved that work-pieces reveal maximum thermal resistance and preservation of exploitation properties, when total closed porosity is within $2 \%-8 \%$, and pore sizes vary within $1-6 \mathrm{mcm}$. Besides, they are more or less of spherical form and are spread equally in the matrix. Conclusion: Thermogradient effect formula was defined for complex form work-pieces, when surfaces in the pieces are transacted several times by angles of various curvature radii.
\end{abstract}

\section{Keywords}

Thermogradient Effect, Matrix Curvature Radius, Parameters, Temperature Field, Thermal Stress, Thermal Expansion

\section{Introduction}

It is known that resistance to thermal- and air-thermal aggression and respectively to thermogradient of composite work-pieces made on ceramic matrix depends greatly not only on the value of the gradient at the mechanical stresses, which are mainly conditioned by the phases present in the material, thermal-processing regime and physical-chemical processes going on in the material during synthesis but also together with other factors, on their form [1] [2] [3] [4].

If we take into consideration the fact that, when the nature of distribution of local mechanical stresses in solid bodies depends substantially on the form of a body, it is apparent that neglect of the form of a piece to thermogradient, will be associated with a big inaccuracy while determining the resistance of any specific work-piece [1] [2]. When we speak of the piece form, first of all, we have to im- 
agine the curvilinear bodies with the surface of various curvature radii, which are mainly associated with the design of composite pieces. Composite materials are often characterized by rather complex profile relief, and in separate sections of its relief we often come across with very small radius curvature surfaces. It is namely pieces of such relief which are characterized by relatively high mechanical stresses, that is, static mechanical stresses [5] [6] [7]. When ceramic piece falls in the field of high thermal gradients the field efficiently acts on the section of a piece, in which mechanical stresses dominate, which is expressed in micro-efficiency, that is, in transformation of micro-cracks into macro-cracks and the final destruction of a piece [1] [2] [8] [9] [10] [11]. The fact is evident even without proving that in real conditions heat transmission is the last factor and temperature gradient between thermal emission and the piece at the border is bigger than the gradient formed in the piece, irrespective of the size of the piece.

\section{The Main Part}

As far as it is known for us, in technical literature available up to now impact of the form of any work-piece on the resistance of thermogradient of pieces has not been elucidated yet. The known Weibull's formula [9] doesn't consider certain definite complex forms of ceramic work-pieces and their effect not only on thermogradient of pieces, but also on their thermal resistance, at large. Likewise, a form of a piece is not considered in Bio's [9] criterion, which characterizes value of temperature gradient between the piece surface and internal sphere. Fourier's [7] formula offers us only coordinates of a spot to be considered. Kingery [8] in his computations for non-stationary regime, when piece surface temperature suffers abrupt alteration from $\mathrm{T} 1$ to $\mathrm{T} 2$, while average temperature of a body remains almost unchanged (that is we deal with thermal shock) and at the same time heat transition tends to infinity-uses the so-called form factor, but physical content is not explained by interpretations. Kingery often introduces the form factor in the formula for thermal resistance.

In most cases these are spherical, cylinder and infinitely flat plates, that is, simple forms. We considered necessary to define formula of thermogradient effect for relatively complex forms, that is, when the piece surfaces are intersections by various curvature radius angle. For determination of a piece resistance to thermal aggression the value of this angle has determining significance. Although we will repeat that in the complex material structure, the composition, texture and many factors have important impact on thermal resistance. Besides, we have to take into consideration that selection of adequate parameter for evaluation of methodology of thermal resistance and its assessment is rather difficult [12]. We think that determination of thermal resistance [13] only by means of the values of mechanical strength at stretching, E-elasticity module and temperature conductivity-a, are not sufficient. Special literature [14]-[19] offers formulas, which are used for evaluation of heat stability of work-pieces. Apparently in those relations alongside with mechanical strength, porosity and thermal stability, we have to consider quantitative evaluation of the above referred para- 
meters. Limit of strength [6] at bending of porcelain material, when it causes its destruction, approximately equals to $56 \mathrm{MPa}$ [20]. If we consider Budworth's data [21] optimal volumetric quantity of pores in the matrix should not exceed $10 \%$, and as a result, its mechanics suffers drastic worsening. At the same time Helga Gollisch-Szibov [22] offers optimal pore sizes $-5 \mathrm{mcm}$. Kingery [8] offers insignificant porosity dependence on the factor of thermal resistance. According to the opinion of Strelov [23] at swift heating, porosity doesn't affect significantly crack formation process.

It is known from practice [3] that increase of porosity in most cases contributes to the elevation of thermal stability, but due to the fact that at this moment mechanical properties are decreased, it is complicated to determine optimal porosity. On the basis of experiments carried out by us by Harcourt [24] method and water cooling at boiling regime, it was proved that work-pieces reveal maximum thermal resistance, when total closed porosity in the matrix is within $0.5 \%$ $-8 \%$, and sizes of pores vary within $1-6 \mathrm{mcm}$. At the same time, they are more or less of spherical form and are spread equally in the matrix. [24], that is, the material is consolidated. We tried to offer explanation for this problem and by the provision of a series of experimental data we formulated empirical formula, which establishes relations between urgent matrix parameters for ceramic materials and composites and coefficient of resistance to thermal gradient of the material (for ceramic materials and composites). Temperature gradient created in the work-piece which is placed in temperature field should be characterized by the effect. Between the bottom of the work-piece and the heat source, there occurs the temperature difference, or the primary gradient. At the same time, temperature field created along the piece height, is parallel to the initial field, and is perpendicular to the secondary one, or on the heat, created on the bottom of the work-piece. Thus, we received secondary temperature difference between heat source and the heat, created on the height of the work piece. Vector direction of both heat sources is on the same side. Thermogradient effect should be conditioned by emission trajectory curvature in temperature field and should be characterized by the coefficient, which shows durability of a piece in thermogradient conditions and speed of temperature equalization in the environment. It is measured in $\mathrm{cm} / \mathrm{sec}$.

$$
K=r \cdot \sigma_{b}(1-\mu) / a \cdot d T / d y \cdot d_{1 / 2} \cdot E \cdot a_{t}
$$

$r$-is for the work-piece curvature radius for selected surface element, $\sigma_{b e n d}$ is mechanics at bending, $\mathrm{MPa} ; \mu$-Poisson coefficient; $a_{t}$-temperature conductivity; $E$-Young's module; a-coefficient of linear expansion, $d T / d y$-thermal gradient for the selected $y$ axis, along which thermogradient occurs, $d_{1 / 2}$-half of piece wall thickness. It is necessary to allow some empiric assumptions, thus, e.g. that the piece from the side of heating should be flat, while the angle of joining of any two planes should be determined by curvature radius, which equals or exceeds

$$
r \geq 0.3 \mathrm{~cm}
$$


Spot of joining of two planes of a piece is computed according to the design, empirically, at 30\% maximum angle. As to the thermal expansion and thermal stress, it is considered that expansion of the work-piece is free, that is, mechanically unlimited, while the stress can be formed not only due to abrupt alteration but also at gradual changes, since at one and the same thermal gradient and at various curvature radii, various stresses will be formed in the piece.

In our case, to test the formula we used the properties of celsian electro-ceramic piece synthesized in $\mathrm{BaO}-\mathrm{Al}_{2} \mathrm{O}_{3}-\mathrm{SiO}_{2}$ system [25] and inserted the above listed properties in the formula by the succession of values given in the formula:

$$
K=0.3 \times 69 \times(1-0.282) / 282 \times 75 \times 3 \times 10-6 \times 140 \times 0.4=0.28 \mathrm{~cm} / \mathrm{sec}
$$

Thus, if we determine universal connection between mechanical and thermal properties of the material, and alongside with it, we'll take into consideration the piece design and wall thickness, we'll be able to compute resistance of a piece to thermal gradient.

\section{Conclusion}

The formula enables us to determine numerical value, which will conform to the resistance of the given work-piece to thermogradient. This latter is computed by the provision of numerical values of the characteristics of the main ceramic materials (composites) used in practice which are given in the formula [26]. Designers of ceramic pieces will be able to use the data, first of all, with the view of selection of thermogradient, if threshold value of thermal resistance of the given material is known.

\section{Conflicts of Interest}

The author declares no conflicts of interest regarding the publication of this paper.

\section{References}

[1] Grathwohl, G. (1993) Mechanische Eigenschaften Konnstruktionswerkstoffe. DGM Information sgesellschaft Verlag.

[2] Munz, D. and Fett, T. (1989) Mechanische Verhalten keramischer Werkstoffe. Springer, Verlag, Berlin, Heidelberg, New York, London, Paris, Tokyo, Hong Kong. https://doi.org/10.1007/978-3-642-51710-5

[3] Maslennikova, G.N. and Kharitonov, F.Ya. (1977) Electro-Ceramic, Resistant to Thermal Shocks. Energy, Moscow.

[4] Davidge, T.G. (1967) Thermal Shock and Fracture in Ceramics. Transactions of the British Ceramic Society, 66, 405-422.

[5] Sobolev, I.D. and Egorov, V.I. (1962) Thermal Fatigue and Thermal Shock. In: Stability and Deformation in Inhomogeneous Temperature Fields. Gosatomizdat, Moscow, 194.

[6] Natsenko, A.I. (1971) Thermal Stability of Brittle Materials. In: Theoretical and 
Technological Researches in the Sphere of Refractory Materials. Collections of Scientific Works of Ukrainian Scientific Researches, Institute of Refractory Materials. Issue: 15, "Metallurgy", Moscow, 189-208.

[7] Mikheev, M.A. and Mikheev, I.M. (1973) Principles of Heat Transfer. Energy, Moscow, 319.

[8] Kingery, V.D. (1963) Measurements at High Temperatures. Metallurizdat, Moscow, 466.

[9] Shvedkov, E.L., et al. (1991) Dictionary of New Ceramic. Naukova Dumka, Kiev, 116-117.

[10] Hornbogen, E. (1992) Werkstoffe. Springer-Verbag, Berlin, Heidelberg, New York, London, Paris, Tokyo, Hong Kong, Barcelona, Budapest.

[11] Hasselman, D.P.H. (1967) Approximate Theory of Thermal Stress Resistance of Brittle Ceramics Involving Creep. Journal of the American Ceramic Society, 50, 454. https://doi.org/10.1111/j.1151-2916.1967.tb15160.x

[12] Kharitonov, F.Ya. and Sherenova, O.A. (1969) Modern Methods of Evaluation of Thermal Stability of Ceramic Materials and Criteria of Its Determination. Heat Resistant Ceramic (Abstracts of Reports of Scientific-Technical Conference, Tiraspol). "Informemelectro", Moscow, 3.

[13] Loffler, W. and Petermann, K. (1968) Dichte weissbrennende Cordieritkeramik als Werkstoff fuer Flammenfestesgeschier. Silikattechnik, 19, 54.

[14] Timoshchenko, S.P. (1946) Strength of Materials. Gostecjizdat, Moscow, 456.

[15] Winkelmann, A. and Schott, O. (1894) Veberthermische Widerstandskoefficienten verschiedener Glaser in ihrer Abhangigkeit von der chemischen Zusammensetzung. Annalen der Physik und Chemie, 51, 730.

[16] Pogodina-Alekseeva, G.I. (1959-60) Reference Book for Machine-Building Materials. Mashgiz, 450.

[17] Bartenov, G.M. and Lioznyanskaya, S.G. (1953) Reference Book for Various Methods of Testing Glasses for Thermal Resistance. Collection of Works of All-Union Sci. Res. Institute of Glass, No. 32, 96-104.

[18] Morozov, E.M. and Fridman, Ya.B. (1962) Thermal Tensions and Evaluation of Their Values. In: Strength and Deformation in Inhomogeneous Temperature Fields, Gosatomizdat, 30 .

[19] Timoshenko, S. and Goodier, I.N. (1951) Theory of Elasticity. McGraw Hill, New York, 250.

[20] Baker, T.C. and Preston, F.W. (1946) Fatigue of Glass under Static Loads. Applied Physics, 17, 170. https://doi.org/10.1063/1.1707702

[21] Budworth, D.W. (1970) Theory of Pore Closure during Sintering. Transactions of the British Ceramic Society, 69, 29-31.

[22] Helga Gollis-Szibov-zum Zusammensetzung der Gefuegedaten und mechanischen Eigenschaften von Porzellan. Dissertation zur Erlengung des Grades eines Doktor Ingenieur. 1979 April. Technische Universitaet Clausthal, s. 3-117.

[23] Strelkov, K.K. (1972) Structure and Properties of Refracrory Material. Metallurgy, 216.

[24] Kovziridze, Z., Hennicke, H.W. and Kharitonov, F. (1998) Thermomechanics of Ceramics Monograph. FH Karlsruhe BRD.

[25] Kovziridze, Z. (1993) Elaboration of Scientific Principles and Technology of Obtaining Celsian and Alumino-Silicate Ceramic by the Use of Barite and Pearlite. 
Thesis for Gaining Scientific Degree of a Doctor of Technics, 104-110.

[26] Formula of Thermogradient Effect (2017) Georgian National Intellectual Property Center "Georgia Patent" (Sakpatenti) Certificate of Deposition. 